\title{
Mikro Parametrelerin Makro Mekanik Kaya Davranıșı Üzerindeki Etkisi: Ayrık Elemanlar Yöntemiyle Model Kalibrasyonu
}

\author{
Effects of Micro Parameters on Macro Mechanical Rock Behavior: \\ Model Calibration Through Discrete Element Method \\ Özge DINCC GöĞÜŞ (D) \\ İstanbul Teknik Üniversitesi, Jeoloji Mühendisliği, İstanbul, Türkiye
}

\section{ÖZ}

Mühendislik yapılarının içinde veya üzerinde inşa edilen kayalarla nasıl bir etkileşim içinde olacağını anlamada sayısal modelleme yöntemleri oldukça etkileyeceği bilgiler sunmaktadır. Ancak bu bilgilerin mevcut kaya ortamını ne denli temsil edici olduğu oluşturulan sayısal modelin güvenilirliğine bağlıdır. Bu nedenle bir modelin oluşturulmasında etkili olan mikro parametrelerin en doğru şekilde kalibre edilmesi ve model sonuçlarının, modelin çözünürlüğ̈̈nden ve/veya boyutlarından bağımsız olması gerekmektedir. Son yıllarda kaya gibi karmaşık katı yapıların mekanik davranışlarının belirlenmesinde yaygın olarak ayrık elemanlar yöntemi (DEM) kullanılmaktadır. Söz konusu çalışmanın amacı, bu yönteme dayanan sayısal bir modelin oluşturulmasında gerekli mikro parametrelerin, bir kayanın makro mekanik özellikleri ve deformasyon davranışı üzerindeki etkisini araştırmaktır. Her bir mikro parametrenin ayrı ayrı ele alındığı çalışmada, Yade açık kaynaklı DEM kodu kullanılarak çok sayıda tek eksenli sıkışma, tek eksenli çekme ve üç eksenli sıkışma dayanım deneyi simülasyonları yapılmıştır. Elde edilen sonuçlar, kayaların tek eksenli sıkışma dayanımının (UCS) öncelikle mikro-kohezyona, tek eksenli çekme dayanımının (UTS) ise birincil olarak partiküller arası çekme dayanımına bağlı olduğunu göstermiştir. Ayrıca bu iki dayanım özelliği mikro-elastisite modülü ve rijitlik oranıyla da güçlü bir etkileşim içindedir. Kayaların deformasyon özelliklerinden olan Young modülü (E) ve Poisson oranı (v) ise doğrudan mikro-elastisite modülü ve rijitlik oranı ile denetlenmektedir. Mikro-içsel sürtünme açısındaki artış kayanın yenilme zarfının eğimini artııırken, dayanım oranının (UCS/UTS) saptanması deney simülasyonları başlamadan önce atanan koordinasyon sayısıyla belirlenmiştir. Bu çalışma sayısal model parametrelerinin birbirleriyle olan etkileşimlerine göre bir kayanın dayanım ve deformasyon özelliklerinin bağlı olduğu koşulları göstermektedir. Elde edilen sonuçlar, mühendislik yapılarının inşasında karşılaşılacak kaya davranışlarını önceden kestirebilen sayısal modellerin geliştirilmesinde uygulanabilir, pratik ve yol gösterici bilgiler sunmaktadır.

Anahtar Kelimeler: Kaya Davranışı, Mikro Parametreler, Mekanik Özellikler, Kalibrasyon, Ayrık Elemanlar Yöntemi (DEM)

\begin{abstract}
The numerical modelling techniques provide quite useful insights about how the interaction between engineering structures and host rocks develop. On the other hand, the representation of the real rock domain depends on the reliability of the numerical model used. For this reason, micro parameters of a model must be calibrated accurately and model results must be irrespective of the model resolution and/or dimension. Recently, the discrete element
\end{abstract}


Dinç Göğüş

method (DEM) is mostly used to determine the mechanical behaviors of the complex solid materials such as rocks. The purpose of this study is to investigate the effects of required micro parameters for developing a numerical model -based on such method- on macro mechanical properties and deformation behaviors of a rock. Every micro parameter is analysed individually by performing a number of uniaxial compressive, uniaxial tensile, and triaxial compressive test simulations through Yade open source DEM code. Obtained results show that the uniaxial compressive strength of the rock (UCS) mostly depends on micro-cohesion while the uniaxial tensile rock strength (UTS) primarily depends on tensile strength between the particles. Furthermore, both strength properties are in relation to the microelastic modulus and stiffness ratio. The deformation properties such as Young's modulus (E) and Poisson's ratio (v) are directly controlled by the micro-elastic modulus and stiffness ratio. The slope of the rock failure envelope is increasing with an increase in micro-internal friction angle and the strength ratio (UCS/UTS) is arranged based on the coordination number assigned at the beginning of the simulation. This study presents the constituents of strength and deformation properties of a rock according to the interaction between the model parameters. The results provide applicable, practical and guiding insights in terms of developing numerical models which predict the rock behaviors before the construction of engineering structures.

Keywords: Rock Behavior, Micro Parameters, Mechanical Properties, Calibration, Discrete Element Method (DEM)

\section{GíRiș}

Bir mühendislik projesinde, o projeye konu olan kaya davranışının operasyon öncesi belirlenmesi ve sonrasında nasıl evrildiği mühendislik çalışmalarının en temel araştırma konusu olmuştur. $\mathrm{Bu}$ amaçla gerçekleştirilen laboratuvar ve arazi deneylerinden elde edilen veriler, ev sahibi kayaya dair oldukça yararlı veriler sunmaktadır. Diğer taraftan bu verilerin bazı durumlarda ölçek etkisine takılarak, daha büyük ortamlar için kayanın nasıl davranabileceğini kestirmede yetersiz kaldı $\breve{g} 1$ durumlarla karşılaşılmış ve söz konusu sorunlar çeşitli çalışmalara da konu olmuştur (Bieniawski, 1968; Heuze, 1980; Medhurst ve Brown, 1998; Deisman vd., 2009). Proje süreleri açısından genellikle bu tür aşamalar uzman kişilerin görüşleriyle geçilmiş, proje gidişatı karşılaşılan sorunlara göre güncellenmiştir.

Son y1llarda sayısal modelleme yöntemleri yalnızca karot ölçeğinde değil, aynı zamanda bölgesel ölçekteki kaya davranışını kestirmede de etkili bir araç olmuştur (Lisjak vd., 2016; Duan vd., 2015; Scholtès ve Donzé, 2015; Duan ve Kwok, 2016). Sonlu elemanlar (FEM), sinır elemanları (BEM), ayrık elemanlar (DEM) yöntemleri mühendislik araştırmalarında sıklıkla kullanılmıştır. $\mathrm{Bu}$ yöntemlerden kaya gibi süreksizlik içeren ortamların modellenmesinde her bir yapısal unsuru ayr1 ayrı ele alabilme avantajı nedeniyle daha çok ayrık elemanlar yöntemi (DEM) tercih edilmektedir. İlk kez Cundall (1971) tarafindan önerilen ve sonraki yıllarda çok sayıda araştırmacının geliştirerek ilerlettiği bu yöntem, kaya davranışını partikül denen ayrik elemanların bir araya gelerek oluşturduğu sistemin (bağlı partikül modeli, BPM) davranışıyla temsil etmektedir. Söz konusu yönteme dayanan literatürdeki bir çok çalışma, kırılgan kayaların yenilme karakteristiklerini ve bu tür kohezyonlu ve sürtünmeli malzemelerde gerilimle tetiklenen deformasyon davranışını anlamada oldukça yararlı bilgiler sunmuştur (Potyondy vd., 1996; Hazzard vd., 2000; Potyondy ve Cundall, 2004; Al-Busaidi vd., 2005; Cho vd., 2007; Wang ve Tonon 2009; Plassiard vd., 2009; Scholtès ve Donzé, 2013). Sayısal modellerin kurulması ve geliştirilmesi uzman kişiler tarafindan oldukça etkili bir şekilde kaya mühendisliği konusunda kullanılmaktadır. Ancak yöntemin uygulanmasının anlaşılabilir olması, farklı araştırmacıların da çalışmalarında yararlanabilmesi veya geliştirilen modellerin 
doğruluğunun test edilmesi açısından son derece önemlidir.

Bir sayısal model kurulurken dikkat edilmesi gereken en temel noktalar aşağıdaki gibi siralanabilir: i. Sayssal modelin öncelikle sınır koşullarından etkilenmemesi gerekmektedir. Özellikle klasik sürekliformülasyona sahip modellerde karşılaşılan bu sorun (De Borst vd., 1993), genellikle DEM tabanlı kodlarda aşılabilmiştir. ii. Partiküllerin bir araya gelmesiyle oluşan sistem, partiküllerin gelişigüzel atanmış olan konumsallığından etkilenmemelidir (Dinç ve Scholtès, 2018). iii. Kurulan sistemin davranışı, model örneğinin boyutları veya çözünürlüğünden bağımsız olmalı (Dinç ve Scholtès, 2018; Dinç Gögüuss, 2020), örnek boyutunun değişmesi modelin davranışını değiştirmemelidir (örneğin lineer-elastik bir davranıştan elasto-plastik bir davranışa geçiş gibi). iv. Üzerinde durulması gereken bir diğer husus ise, modellerinin doğru kaya dayanım oranlarını (tek eksenli sıkışma dayanımı, UCS / tek eksenli çekme dayanımı, UTS) yansıtması, kayanın rijitliğine göre bu oranların artırılıp azaltılarak ayarlanabilmesidir (Potyondy, 2012; Scholtès ve Donzé, 2013; Ding ve Zhang, 2014). Tüm bu koşullar yerine getirildikten sonra, artık modelin fiziksel özelliklerine (model boyutu, partikül (ayrık eleman) yarıçapı, porozite vb.) modelin maruz kalacağı gerilim koşullarına ve son olarak model parametrelerinin atanmasina odaklanılabilir.

$\mathrm{Bu}$ çalışmanın amacı, ayrık elemanlar yöntemine (DEM) dayanan Yade açık kaynaklı DEM koduyla geliştirilen bir sayısal modelde, modelin oluşturulmasından bir kayayı temsil edecek şekilde davranmasına kadar geçen sürede kritik parametreleri araştırmaktır. DEM tabanlı modellerin mikro parametrelerinin (kohezyon, c; çekme dayanımı, t; içsel sürtünme açısı, $\phi$; rijitlik oranı, P; elasite modülü, E ve partiküller arası bağ sayıs1, N) bir kayanın makro mekanik özellikleri üzerinde (tek eksenli sıkışma dayanımı, UCS; tek eksenli çekme dayanımı, UTS; deformasyon modülü, E ve Poisson oranı, v) nasıl bir etki yarattığını anlamak, çalışmanın temelini oluşturmaktadır. Bu amaçla çok sayıda laboratuvar deneyinin simülasyonu sayısal ortamda gerçekleştirilerek, sayısal bir modelin kalibrasyonu sırasında karşılaşılan durumlar incelenmiştir. Söz konusu kalibrasyon sürecinde rijit ve sert bir kaya türünü temsil eden Forsmark granitlerinin (İsveç) laboratuvar verileri kullanılmıştır (Lanaro ve Fredriksson, 2005; Jacobsson, 2007; Glamheden vd., 2008). Model sonuçlarından elde edilen bulgular alt başlıklar altında ayrıntılı olarak analiz edilmiştir. Söz konusu çalışma pratik ve ayrıntılı veriler sağladığından kaya mühendisliğinde gün geçtikçe daha çok ihtiyaç duyulan sayısal modelleme yöntemlerinin kullanımı için önemli yol gösterici ve pratik bilgiler sunmaktadır.

\section{MATERYAL VE YÖNTEM}

$\mathrm{Bu}$ çalışmada sayısal modelleme yöntemlerinden ayrık elemanlar yöntemine dayalı Yade açık-kaynaklı DEM kodu (Šmilauer vd., 2015) kullanılmış ve model kalibrasyonu için laboratuvar çalışması ayrıntılı olarak yapılmış olan Forsmark granitleri seçilmiştir.

İlk olarak Potyondy ve Cundall (2004) tarafindan önerilen ve ilerleyen y1llarda Scholtès ve Donzé (2013) tarafından modifiye edilen bağlı partikül modeli (BPM) söz konusu DEM platformuna entegre edilmiştir. Diğer klasik partikül-tabanlı modellerde olduğu gibi, burada da kaya malzemesi farklı boylara sahip (polidispers dağılmış) rijit ve küresel tanelerin (partiküllerin) birbirine bağlı olduğu bir yapıyla temsil edilmektedir (Şekil 1). Partiküller, ayrik 
elemanlar (DE) olarak da ifade edilirler ve elastikkır1lgan temas kanununa (elastic-brittle contact law) göre birbiriyle etkileşim halindedirler. Bunu sağlamak amacıyla kullanılan etkileşim oranı $\left(\gamma_{\text {int }}\right)$, partiküller bir araya gelip de sayısal model ortaya çıkmadan önce belirlenmiş olur.

$$
\mathrm{D}_{\text {eq }} \leq \gamma_{\text {int }} *\left(\mathrm{R}_{\mathrm{x}}+\mathrm{R}_{\mathrm{y}}\right)
$$

Yukarıdaki ilişkide $D_{\text {eq }}$, yarıçapı $R_{x}$ ve $R_{y}$ olan $\mathrm{x}$ ve y partiküllerinin birbirine olan ilksel uzaklığıdır. $\gamma_{\text {int }}$ başlangıçtaki etkileşim halinde bulunan bağ sayısını $(\mathrm{N})$ kontrol eder ve kaya malzemesini oluşturan modelin içindeki partikül sayısından tamamen bağımsızdır. Klasik DEM modellerinin aksine bu özellikle $\left(\gamma_{\text {int }}\right)$, simülasyon henüz başlamadan her bir partikül başına düşen ortalama bağ sayısı (N) belirlenebilmektedir. Dolayısıyla bu platformda yumuşak kayalardan sert kayalara kadar doğru dayanım oranında (tek eksenli sıkışma dayanımı UCS/tek eksenli çekme dayanımı UTS) her türlü kaya malzemesinin modellenmesi mümkündür. Örneğin, $\gamma_{\text {int }} 1$ ' e yaklaştığında partiküller arası kenetlenme derecesi azalır ve bu durum onun göreceli olarak daha zayıf bir kaya malzemesini temsil etmesi anlamina gelir. Tam tersi durumda ise yani $\gamma_{\text {int }}$ 1' den ne kadar büyükse kayanın sertlik derecesi (veya UCS/UTS oranı) daha çok artmaktadır. Burada dikkat edilmesi gereken bir nokta, $\gamma_{\text {int }}$, nin maksimum tane çap $1\left(\mathrm{R}_{\max }\right)$ ile minimum tane çap1 $\left(\mathrm{R}_{\text {min }}\right)$ arasındaki orana göre belirlenmesidir (örneğin bu çalışmada $\mathrm{R}_{\max } / \mathrm{R}_{\min }=2$ ve $\gamma_{\text {int }} \leq$ 1.5 'dir). Diğer bir konu ise partiküller arasındaki bağ koptuğunda, ortamın gözenekliliğindeki değişimin en aza indirilebilmesi için tüm partiküllerin bir araya gelmesiyle oluşan yapının yoğunluğunun, simülasyonun en başında maksimum seviyede ayarlandiğından emin olunmasidır (Scholtès ve Donzé, 2013).

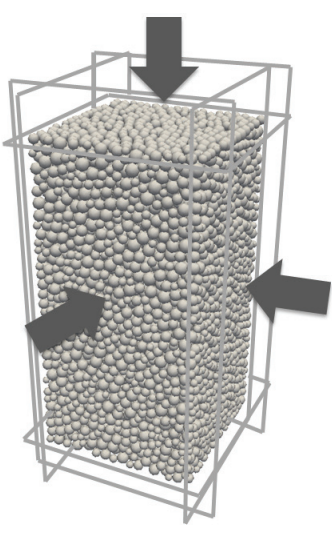

a)

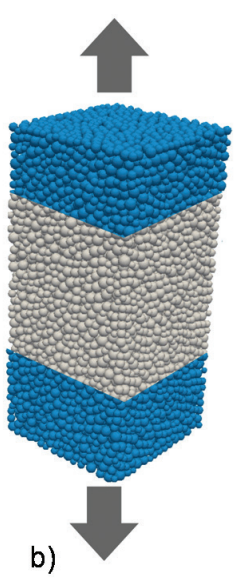

b)
Şekil 1. Bağlı partikül modeli (BPM) a) üç eksenli sıkışma deneyi b) tek eksenli çekme deneyi simülasyonunun şematik gösterimi.

Figure 1. Bonded particle model (BPM) configurations of a) triaxial comrepressive test simulation b) uniaxial tensile test simulation.

Partiküller arasına etki eden kuvvetler normal $\left(\mathrm{F}_{\mathrm{n}}\right)$ ve makaslama $\left(\mathrm{F}_{\mathrm{s}}\right)$ bileşeni olarak ikiye ayrılır (Şekil 2). Normal eksende $F_{n}$ şu şekilde hesaplanmaktadır:

$\mathrm{F}_{\mathrm{n}}=\mathrm{k}_{\mathrm{n}}^{*} \mathrm{u}_{\mathrm{n}}$

$k_{n}=2 Y * \frac{R_{x} * R_{y}}{R_{x}+R_{y}}$

Burada $\mathrm{k}_{\mathrm{n}}$ eş değer elastisite modülün (Y) ( $\mathrm{Pa}$ cinsinden) bir fonksiyonu olan normal rijitliği, $u_{n}$ ise normal rölatif yer değiştirmeyi temsil etmektedir. S1kışma yükü altındayken, $F_{\mathrm{n}}$ sınırlı değildir ve süresiz olarak artış gösterebilir. Çekme rejimi altındayken ise, $\left(\mathrm{F}_{\mathrm{n} \text {,max }}=\mathrm{t} * \mathrm{~A}_{\text {int }}\right)$ eşik değerine kadar artabilir. Buradaki t partiküller arası çekme dayanımıdır (Pa cinsinden). Partikül boyutlarına bağlı olan yüzey ise $\mathrm{A}_{\text {int }}=\pi *$ $\left[\min \left(\mathrm{R}_{\mathrm{X}} ; \mathrm{R}_{\mathrm{y}}\right)^{2}\right]$ eşitliğinden hesaplanmaktadır. $\mathrm{F}_{\mathrm{n}}$ $\geq \mathrm{F}_{n, \max }$ olduğunda, partiküller arasındaki bağ kopar ve bağın olduğu yerde bir çekme çatlağ 1 (mod I) gelişir (Şekil 2). 
Makaslama ekseninde ise $F_{s}$ tetikleyici kuvvet olup, artımsal olarak;

$\mathrm{F}_{\mathrm{s}}=\mathrm{F}_{\mathrm{s}, \mathrm{t}}-\Delta_{\mathrm{t}}+\mathrm{k}_{\mathrm{s}}^{*} \Delta \mathrm{u}_{\mathrm{s}}$

eşitliğinden hesaplanır. $\mathrm{Bu}$ ilişkide $\mathrm{k}_{\mathrm{s}}$ makaslama riitliğidir ve $\mathrm{k}_{\mathrm{s}}=\mathrm{P} * \mathrm{k}_{\mathrm{n}}$ eşitliğinden belirlenmektedir. $\mathrm{P}$ ise bir model sabitidir ve değeri 0 ile 1 arasında değişmektedir $(0<\mathrm{P}<$ 1). $\Delta u_{\mathrm{s}}$ rölatif artımsal yer değiştirme miktarı ve $\mathrm{F}_{\mathrm{s}, \mathrm{t}-\Delta \mathrm{t}}$ bir önceki zaman-adımındaki makaslama kuvvetidir. Maksimum izin verilebilir makaslama kuvveti $\quad \mathrm{F}_{\mathrm{s}, \max }$ Mohr-Coulomb kriterinden belirlenmektedir.

$\mathrm{F}_{\mathrm{s}, \max }=\mathrm{c} * \mathrm{~A}_{\mathrm{int}}+\mathrm{F}_{\mathrm{n}} * \tan (\phi)$

Bilindiği gibi yukarıda c kohezyon $(\mathrm{Pa}) \mathrm{ve}$ $\phi\left(^{\circ}\right)$ içsel sürtünme açını temsil etmektedir. $\mathrm{F}_{\mathrm{s}}$ $\geq \mathrm{F}_{\mathrm{s} \text {,max }}$, olduğunda makaslama yenilmesi gelişir ve partiküller arasındaki bağın olduğu yerde bir makaslama çatlağı (mod II) oluşur (Şekil 2).

Yöntemin dinamik formülasyonu nedeniyle, kinetik enerjiyi dağıtmak ve simülasyonların yarı-statik koşullar altında gerçekleşmesini sağlamak amacıyla, global viskoz olmayan bir sönümleme parametresi kullanılmıştır. Yapılan tüm simülasyonlarda sönümleme sabiti 0.4 olarak seçilmiştir.

\section{MODEL KALIBBRASYONU}

Sayısal modelin kalibrasyonuna konu olan kaya türü, daha önce laboratuvar çalışması İsveç Nükleer Yakıt ve Atık Depolama Şirketi (Swedish Nuclear Fuel and Waste Management Company, SKB) ve çeşitli araştırmacılar (Lanaro ve Fredriksson 2005; Jacobsson, 2007; Glamheden vd., 2008) tarafindan ayrıntıl1 olarak yapılmış olan Forsmark granitleridir. Günümüzde İsveç' de radyoaktif atık depolamada "depolama kayası" olarak ele alınan Forsmark granitleri, düşük gerilim koşullarında kırılgan bir davranış sergilerken, yanal gerilimin $20 \mathrm{MPa}$ 'nın üzerine çıktığ 1 durumlarda kısmi elasto-plastik bir davranışa geçiş yapmaktadır. Gerilimdeformasyon davranışlarından yola çıkarak, söz konusu kayaya ait laboratuvar deney sonuçları ve bu sonuçlara göre kalibre edilmiş mikro parametreler (c, t, $\phi, \mathrm{P}, \mathrm{Y}$ ve N) sırasıyla Çizelge 1 ve Çizelge 2' de verilmiştir.
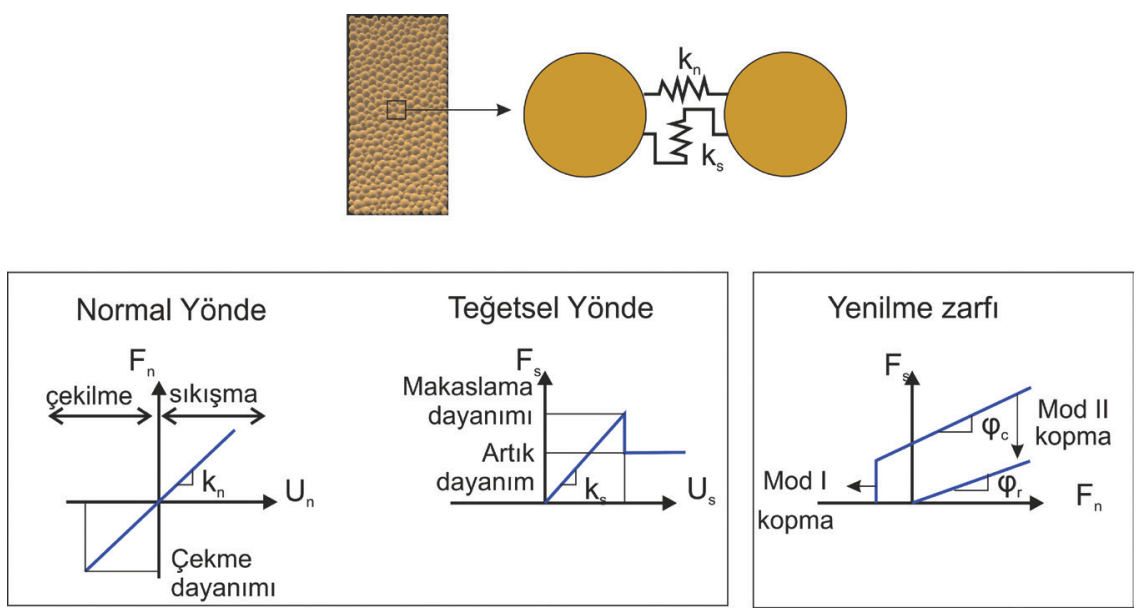

Şekil 2. Ayrık elemanlar (partiküller) arasındaki normal ve makaslama etkileşim kuvvetleri (Scholtès ve Donzé, 2012' den değiştirilerek).

Figure 2. Normal and shear interaction forces between discrete elements (particles) (modified from Scholtès and Donzé, 2012). 
Dinç Göğüş

Çizelge 1. Forsmark granitlerinin laboratuvar (Lanaro ve Fredriksson, 2005; Jacobsson, 2007; Glamheden vd., 2008) ve DEM analizlerinden elde edilen makro mekanik özellikleri (Dinç Göğüş, 2020).

Table 1. Macro mechanical properties of Forsmark granite from laboratory (Lanaro and Fredriksson, 2005; Jacobsson, 2007; Glamheden et al., 2008) and DEM analyses (Dinç Göğüş, 2020).

\begin{tabular}{lllll}
\hline Parametre & UCS $(\mathrm{MPa})$ & UTS $(\mathrm{MPa})$ & E $(\mathrm{GPa})$ & $v(-)$ \\
\hline Laboratuvar & $223 \pm 22$ & $14 \pm 2$ & $76 \pm 3$ & $0.24 \pm 0.04$ \\
\hline DEM & 199 & 16 & 75 & 0.13 \\
\hline
\end{tabular}

Çizelge 2. Kalibre edilen DEM sayısal modelin mikro mekanik parametreleri (Dinç Göğüş, 2020).

Table 2. Micro mechanical parameters of the calibrated DEM model (Dinç Göğ̈̈ş, 2020).

\begin{tabular}{lc}
\hline Parametre & 70 \\
\hline Elastik Modülü Y $(\mathrm{GPa})$ & 0.4 \\
Rijitlik oranı P $(-)$ & 13 \\
Çekme dayanımı t $(\mathrm{MPa})$ & 130 \\
Kohezyon c $(\mathrm{MPa})$ & 5 \\
Sürtünme açısı $\phi\left({ }^{\circ}\right)$ & 13 \\
Koordinasyon sayısı N $(-)$ & \\
\hline
\end{tabular}

Kalibrasyonu yapılan DEM modeli $1 \times 2 \times 1$ model birim boyutlarında olup 10,000 partikülden oluşmaktadır (Şekil 1). Model sonuçlarının çözünürlük (partikül sayısı) ve model boyutlarındaki değişimlerden etkilenmediği ayrıntılı hassasiyet analizleriyle onaylanmıştır (Dinç Göğüş, 2020).

Bir modelin kalibrasyonu, gerilim deformasyon davranışları ve bu davranışlardan elde edilen mekanik özellikleri, gerçek kayanın davranış ve özelliklerini temsil edinceye kadar devam etmelidir. Dolayısıyla bu süreç oldukça uzun olup çok sayıda iterasyon ve simülasyonu beraberinde getirmektedir. Bu süreci kısaltmak için önerilecek pratik yolların birçok mühendis ve araştırmacı için yararlı olacağı düşünülmektedir.

Genel olarak ayrık elemanlar yöntemine dayalı bir modelde mikro parametrelerin makro özellikler üzerindeki etkisi aşağıdaki gibi özetlenebilir:

- $\quad \mathrm{t}$, partiküllerin çekme dayanımı olup UTS değerini kontrol ederken; c, UCS değerini etkilemektedir.

- $\phi$, kayanın yenilme zarfının eğimini kontrol eder ve doğrudan üç eksenli sıkışma deneyi simülasyonlarında belirlenir.

- Y, doğrudan kaya malzemesinin Young modülünü (E) kontrol ederken $\mathrm{P}, \quad\left(\mathrm{k}_{\mathrm{n}} /\right.$ $\mathrm{k}_{\mathrm{s}}$ ) değerine eşit olup Poisson oranını (v) etkilemektedir. Her iki makro-parametre tek eksenli ve üç eksenli sıkışma deneyi simülasyonlarından belirlenmektedir. Bunun yanı sıra doğrudan çekme deneyi simülasyonlarında çekme rejimi altındaki deformasyon modülü $\left(\mathrm{E}_{\text {çekme }}\right)$ de elde edilebilmektedir. $\mathrm{E}_{\text {cekme }}$ değerinin genellikle sayısal modelleme kalibrasyonlarında ihmal edildiği görülmüştür. Bu durumun en bilinen nedeni, laboratuvar koşullarında doğrudan çekme dayanımı deneyinin yapılmasındaki zorluklardan kaynaklanmaktadır. Çoğunlukla örnek hazırlama ve uygulamadaki pratikliği açısından kayaların çekme dayanımları dolaylı yollardan (Brazilian deneyi, bükülme deneyi vb.) elde edilmekte, söz konusu koşullar altında $\mathrm{E}_{\text {cekme }}$ parametresinin belirlenmesi mümkün olmamaktadır. Ancak bu çalışma kapsamında mikro 
parametrelerin $\mathrm{E}_{\text {çekme }}$ değeri üzerindeki rolü de araştırılmıştır.

- N, parametresi (UCS/UTS) oranına göre simülasyon başlamadan önce belirlenmektedir.

Yukarıda da görüldüğü gibi, bahsedilen 6 parametrenin kayaların UCS, UTS, E ve $v$ özelliklerindeki etkisi kabaca bilinirken, hangi koşullar altında bu etkileşimin bittiği veya güçlendiği konusunda net bir çalışma mevcut değildir. Özellikle partikül tabanlı ayrık elemanlar kodları (Yade, PFC, LIGGGHTS vb.) her ne kadar süreksiz ortamların davranışını belirlemede güçlü bir araç olsa da, bu kodlarla oluşturulan modellerde malzeme davranışının, partiküllerin bir arada bulunduğu mikroyapıdan etkilenmeksizin aynı davranışı (trendi) sergilemesi gerekmektedir. Aşağıda her bir mikro parametrenin makro özellikler üzerinde nası1 rol oynadığ ayrıntılı bir şekilde analizlerle verilmiş ve bu analizlerden kayaların dayanım ve deformasyon özelliklerine göre kalibrasyon sırasında kullanılabilecek pratik bilgiler sunulmuştur.

\section{MODEL SONUÇLARI}

\section{Mikro-Kohezyon (c) ve Mikro-Çekme Dayanımı (t)}

Bir kaya modelini oluşturan ayrık elemanların bir arada bulunması her bir partiküle atanan kohezyon (c) ve çekme dayanım (t) değerlerine bağlıdır ve genel olarak bu parametrelerin kaya modelinin makro tek eksenli sıkışma (UCS) ve çekme dayanımını (UTS) denetlediği bilinmektedir (Scholtès ve Donzé, 2013; Hamdi vd., 2017; Moosavi vd., 2018). Partiküllerin bir arada uyumlu bir şekilde çalıştığ 1 sistemde, yukarıda da belirtildiği gibi maksimum makaslama kuvveti $\left(\mathrm{F}_{\mathrm{s}, \max }\right)$ aşıldı̆̆ında, partiküller arasındaki bağ kopar ve bağın koptuğu yerde makaslama çatlağ ; maksimum normal kuvvetin $\left(\mathrm{F}_{\mathrm{n} \text {,max }}\right)$ aşıldığ1 durumda ise, bağ yerinde çekme çatlağı gözlemlenmektedir (Şekil 2). Dolayısıyla bir kayada deformasyon süreçleri ve hasar miktarı mikro çatlakların yoğunluğuna ve biriktiği bölgelere bağlıdır (Pardoen vd., 2015; Dinç ve Scholtès, 2018; Dinç Gögüus, 2020). (c/t) oranı belirlenirken söz konusu kayanın yumuşak veya sert oluşu göz önünde tutulmalıdır. Çünkü bu oran, aynı zamanda o kayanın makaslama, sıkışma ve çekme gerilimlerine karşı nasıl bir davranış sergileyeceğinin ve deforme olacağının da göstergesidir. c ve $\mathrm{t}$ değerleri tek eksenli sıkışma ve çekme dayanımı deneyi simülasyonlarından belirlenmektedir.

Şekil 2'de farklı (c/t) oranlarının kayanın UCS ve UTS değerleri üzerindeki etkisi gösterilmiştir. Çizelge 2'deki değerler referans olmak üzere, yalnızca c parametresindeki artışla (c: 13, 65, 130, 195, 260 ve $1300 \mathrm{MPa}$ ) UCS değerinde de bir artma olduğu gözlenmektedir (Şekil 3a). Ancak bu artış (c/t) $\geq 10$ olduğunda (c $\geq 130 \mathrm{MPa}$ koşulunda) UCS üzerinde artık herhangi bir etki yaratmamaktadır. UTS değeri ise c kontrollü olan (c/t) oranındaki değişimlerden etkilenmemektedir (UTS = 16 MPa) (Şekil 3b). Diğer taraftan $\mathrm{t}$ değerinin artmasina ( $\mathrm{t}: 10,13$, $15 \mathrm{MPa})$ bağlı olarak değişen $(\mathrm{c} / \mathrm{t})$ oranları sadece UCS değerini değil, aynı zamanda UTS değerini de etkilemiştir. Paydanın büyümesinden kaynaklanan (c/t) oranındaki azalma, hem UCS, hem de UTS üzerinde bir artışa neden olmuştur (Şekil 3c, d ve Çizelge 3).

$\mathrm{Bu}$ analizlerden elde edilen en önemli çıkarım, (c/t) oranının atanmasında öncelikle kayanın (UCS/UTS) oranına bakılması gerektiğidir. Eğer (UCS/UTS) $\approx 10$ ise kalibrasyon öncelikle $(\mathrm{c} / \mathrm{t}) \approx 10$ değerinden başlamalıdır. 
Dinç Göğüş
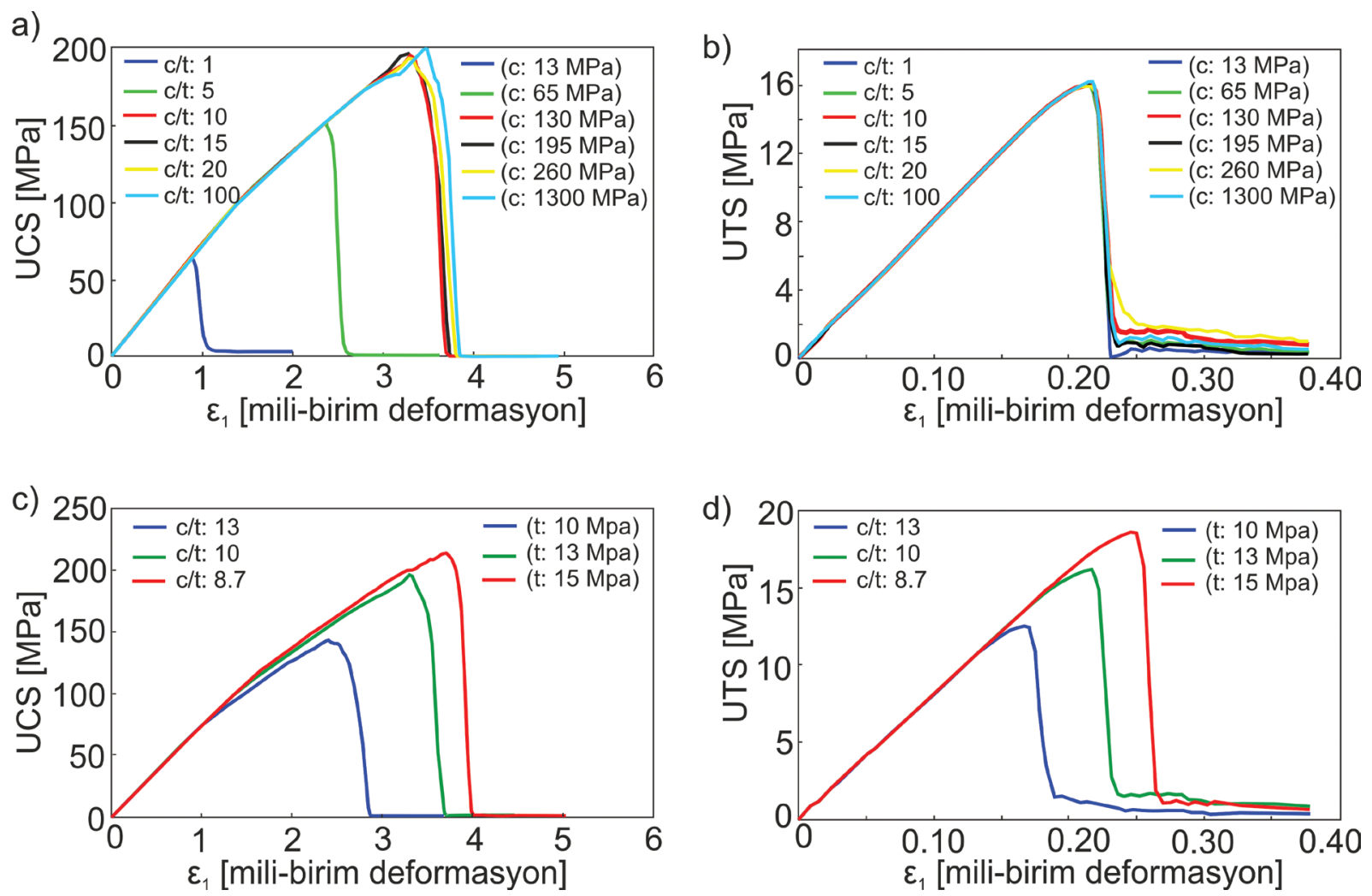

Şekil 3. Partiküllerin kohezyon (c) ve çekme dayanımının (t) makro kaya dayanımı üzerindeki etkileri a) c' nin UCS üzerindeki etkisi b) c' nin UTS üzerindeki etkisi c) t' nin UCS üzerindeki etkisi d) t' nin UTS üzerindeki etkisi.

Figure 3. The effects of cohesion (c) and tensile strength ( $t$ ) of particles on macro rock strength a) effect of $c$ on UCS b) effect of $c$ parameter on UTS c) effect of t on UCS d) effect of t on UTS.

\section{Mikro-İçsel Sürtünme Açısı ( $\phi)$}

Partiküller arasındaki içsel sürtünme açısının $(\phi)$ dayanım üzerinde nasıl bir rol oynadığını belirlemek için öncelikle $\phi$ ' nin farklı değerleri için $\left(5^{\circ}, 10^{\circ}, 20^{\circ}\right.$ ve $\left.40^{\circ}\right)$ tek eksenli sıkışma ve çekme dayanımı deney simülasyonları yapılmıştır. Model sonuçları $\phi$ ' deki artışın dayanım özellikleri üzerinde herhangi bir değişikliğe neden olmadığını göstermiştir (Şekil 4a, b). Sadece $\phi=40^{\circ}$ iken UCS değeri yaklaşık $10 \mathrm{MPa}$ 'ık bir artışla $210 \mathrm{MPa}$ olarak değişmiştir (Şekil 4a). Bu durumda partiküllerin $\phi$ değeri, kayanın makro ölçekteki (laboratuvar ölçeğindeki) makaslama veya üç eksenli sıkışma deneylerinden elde edilen $\phi_{\text {makro }}$ için olduğu gibi yenilme zarfinın eğimiyle ilişkilidir. $\mathrm{Bu}$ nedenle farklı yanal basınçlar altında $\left(\sigma_{3}=2,7,10,12,20\right.$ $\mathrm{MPa})$ gerçekleştirilen üç eksenli sıkışma deneyi simülasyonlarından doruk dayanım değerlerine göre kayanın yenilme zarfı belirlenmiştir (Şekil 4c). Laboratuvar değerleri (Lanaro ve Fredriksson, 2005; Glamheden vd., 2008) $\phi=$ $5^{\circ}$ değeriyle örtüşmekte olup $\phi$ ' nin artmasına bağlı olarak yenilme zarfının eğimi de artış göstermektedir.

Burada dikkat edilmesi gereken husus, $\phi$ değerinin kayaların makro makaslama dayanım özelliklerinden olan $\phi_{\text {makro }}$ içsel sürtünme açısıyla 
karıştırılmamasıdır. Örneğin sağlam granitik bir kayada $\Phi_{\text {makro }} 45^{\circ}$ 'ye kadar çıkabilirken, kumtaşları için bu değer $25-30^{\circ}$ olabilmektedir (Goodman, 1989). Her ne kadar $\phi$ ve $\phi_{\text {makro }}$ benzer şekilde çalışsa da (yenilme zarfının eğimini kontrol ederek), $\phi$ değerinin her bir partikül için atanan mikro-içsel sürtünme açısı olduğu unutulmamalı ve bu değerin düşük yada yüksek olmasının kayanın $\phi_{\text {makro }}$ değeriyle ilişkisinden kaynaklanmadığı bilinmelidir. Kalibrasyondaki $\phi$ değerine doğrudan üç eksenli sıkışma deneyi simülasyon sonuçlarına göre karar verilmelidir.

\section{Rijitlik Oranı (P)}

Daha önceki bölümlerde bahsedildiği üzere, $P$ bir sabit olup partiküllerin rijitlik oranını temsil etmekte ve $\left(\mathrm{k}_{\mathrm{n}} / \mathrm{k}_{\mathrm{s}}\right)$ ilişkisinden belirlenmektedir. Rijitlik oranı yüksek olan bir malzemenin dayanımı yüksek olurken, deformasyona uğraması ise daha zorlayıcı olacaktır. Bu durumda P' nin makro mekanik kaya özelliklerinin tümü üzerinde bir etkisi olması beklenmektedir. Tek eksenli sıkışma ve çekme dayanımı test simülasyonlarında $\mathrm{P}$ için $0.2,0.4$ ve 0.6 değerleri
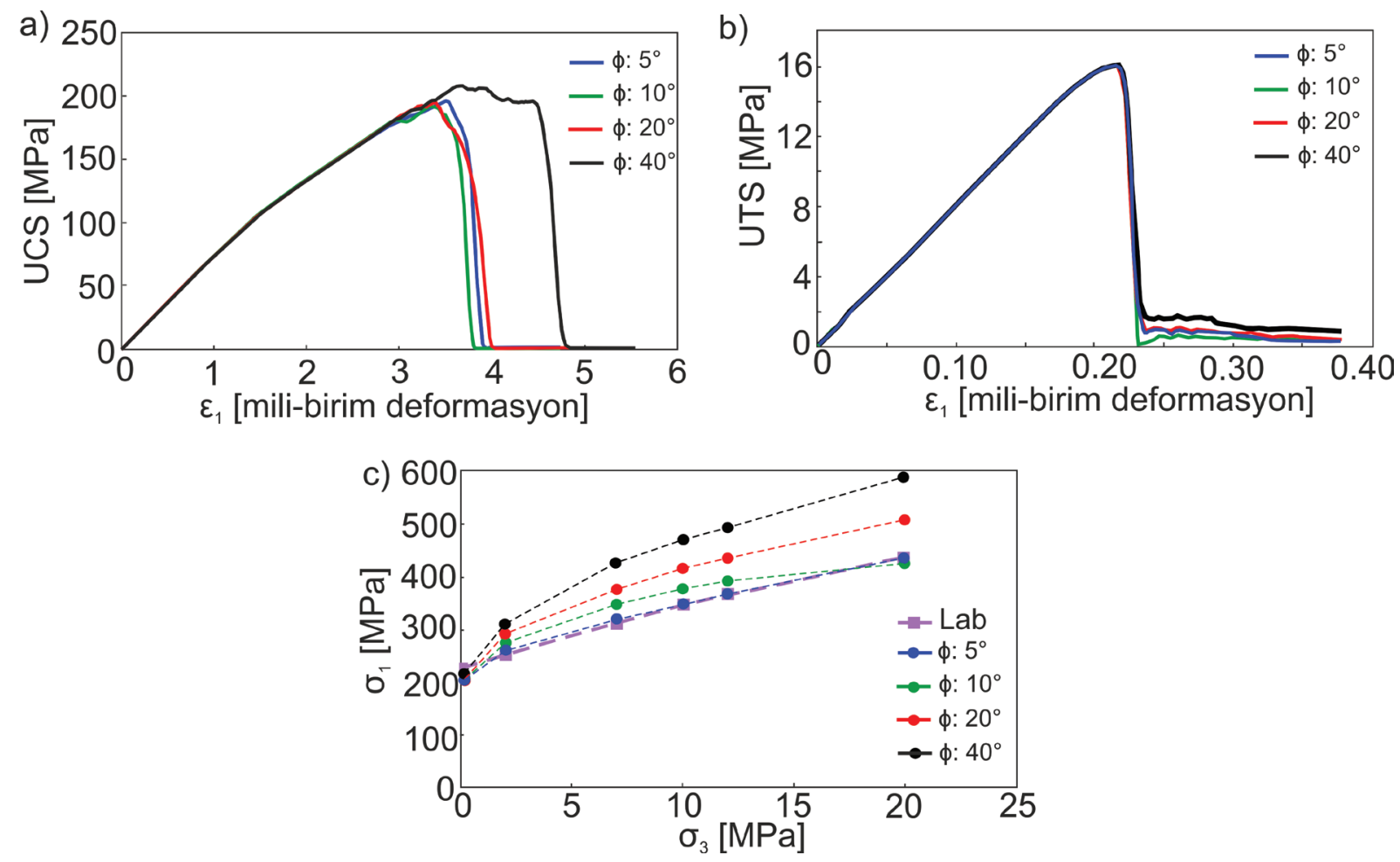

Şekil 4. Partiküller arası içsel sürtünme açısının $(\phi)$ dayanım ve yenilme zarfı üzerindeki etkileri a) $\phi$ ' nin UCS üzerindeki etisi b) $\phi$ ' nin UTS üzerindeki etkisi c) $\phi$ ' nin Hoek-Brown yenilme zarfı üzerindeki etkisi (Lab: laboratuvar verileri; Lanaro ve Fredriksson, 2005; Glamheden vd., 2008'den).

Figure 4. The effects of internal friction angle of particles ( $\phi)$ on rock strength and failure envelope a) effect of $\phi$ on $U C S$ b) effect of $\phi$ on UTS c) effect of $\phi$ on the Hoek-Brown failure envelope (Lab: laboratory data by Lanaro and Fredriksson, 2005; Glamheden et al., 2008). 
atanmış ve P'nin artışıyla hem UCS hem de UTS değerleri yükselmiştir (Şekil 5a, b). Bu durum (UCS/UTS) oranını da artırırken (P: 0.2 için 6.78; P: 0.4 için 12.43 ve P: 0.6 için 14.86) kaya davranışı daha elastik-kırılgan bir eğilime geçiş yapmıştır. Deformasyon modülleri ( $\mathrm{E}$ ve $\mathrm{E}_{\text {çekme }}$ ) benzer şekilde $\mathrm{P}$ oranı ile artışa geçmiştir. Ancak Poisson- oranı (v) P ile ters orantılıdır (Şekil 5c). P oranı artarken, $v$ değeri azalmaktadır (Çizelge $3)$.

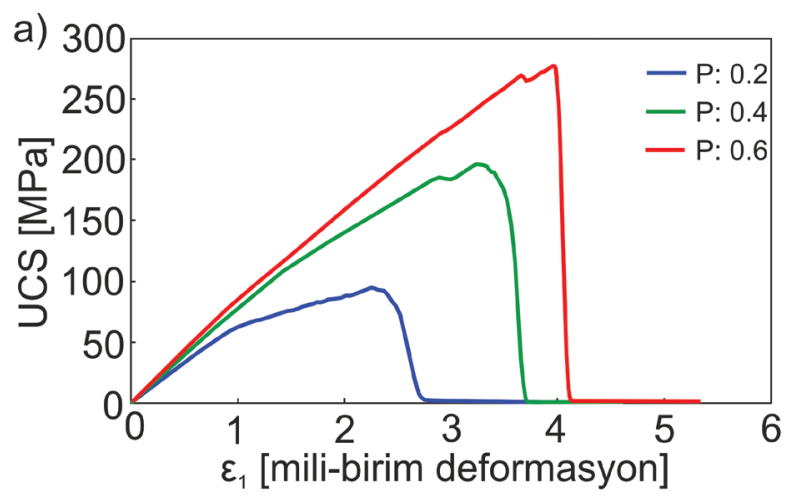

Böyle bir koşulda sayısal model kalibrasyonunun en kritik noktasını rijitlik oranının belirlenmesi olduğu anlaşılmıştır. Kalibrasyonun oldukça zaman alıcı bir süreç olması nedeniyle, bu süreyi kısaltmak için pratik bir yol olarak rijitlik oranının atanmasında (UCS/ UTS) oranından bir yaklaşım geliştirilebilir. Örneğin yumuşak bir kaya için (UCS/UTS $\approx 4$ - 5) P: 0.1' den başlatılırken, daha sert bir kaya için (UCS/UTS $\approx 10$ - 12) bu değer P: 0.4'e çekilebilir.

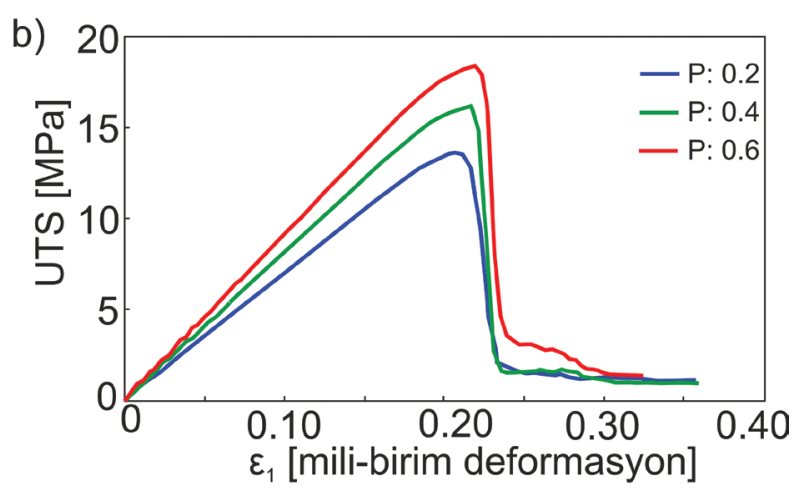

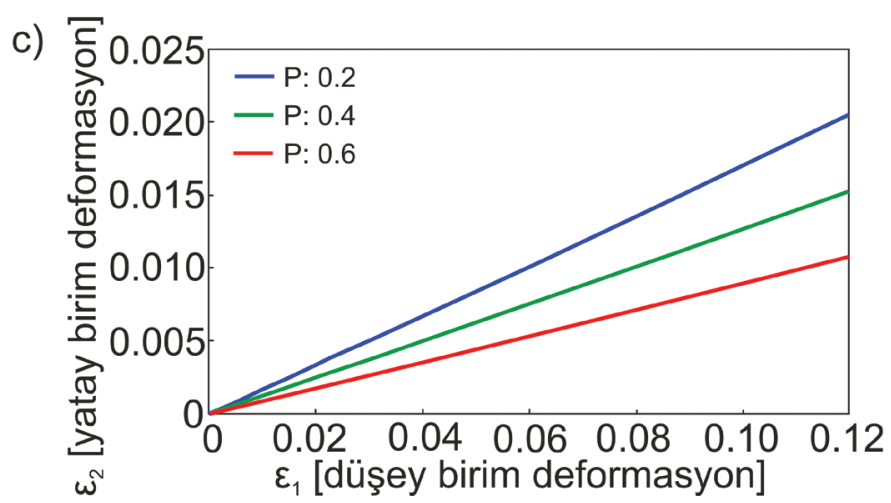

Şekil 5. Rijitlik oranının (P) dayanım ve deformasyon özellikleri üzerindeki etkileri a) P' nin UCS ve E üzerindeki etkisi $(\tan \alpha=E)$ b) P' nin UTS ve $\mathrm{E}_{\text {çekme }}$ üzerindeki etkisi $\left(\tan \alpha=\mathrm{E}_{\text {cekme }}\right)$ c) P'nin $v$ üzerindeki etkisi.

Figure 5. The effects of stiffness ratio $(P)$ on rock strength and deformation properties a) effect of $P$ on UCS and $E$ $(\tan \alpha=E) b)$ effect of $P$ on UTS and $E_{\text {tensile }}\left(\tan \alpha=E_{\text {tensile }}\right)$ c) effect of $P$ on $v$. 


\section{Elastisite Modülü (Y)}

Bir önceki bölümde bahsedilen rijitlik temelde partiküllerin elastisite modülü (Y) ile de bağlantılıdır. Çünkü normal rijitlik değeri olan $k_{n}$, $Y^{\prime}$ nin bir fonsiyonu olarak çalışmaktadır. Tek eksenli sıkışma ve çekme dayanımı deney simülasyonlarında $\mathrm{Y}^{\prime}$ nin farklı değerlerinin (Y: 60, 70, $80 \mathrm{GPa}$ ) kaya dayanım ve deformasyon davranışları üzerindeki rolü incelenmiştir. Genel olarak Y değerinde artış veya azalışlar dayanım özellikleri üzerinde bir etki yaratmamıştır (Şekil 6a, b). Buna karşın Y parametresinin kaya deformasyon süreçleriyle doğrudan ilişkili olduğu belirlenmiştir. Y' nin

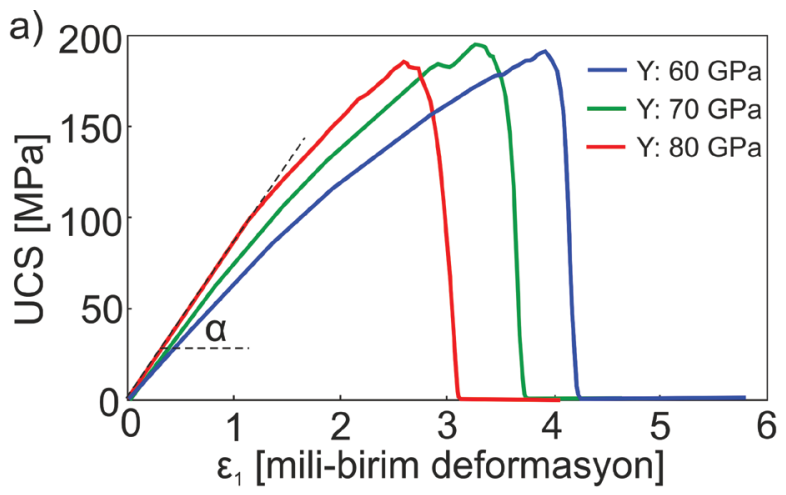

artmasına bağlı olarak gerilim-deformasyon eğrisinin lineer-elastik kısmında eğimin de arttığ 1 gözlemlenmiş, bu durum beraberinde $\mathrm{E}_{\text {ve }} \mathrm{E}_{\text {çekme }}$ parametrelerinin artışını getirmiştir (Çizelge 3). Diğer taraftan aynı $\mathrm{P}$ parametresinde olduğu gibi, Y ile Poisson oranı (v) ters orantılı bir ilişki sunmuş, Y değerlerindeki artışla $v$ değerleri azalmıştır (Şekil 6c ve Çizelge 3).

Buradan elde edilen sonuçlara göre; Y değerinin her $10 \mathrm{GPa}$ ' lık artışı, E değerinde yaklaşık $10 \mathrm{GPa}$ ' lık; $\mathrm{E}_{\text {çekme }}$ için ise $5 \mathrm{GPa}$ ' lık bir artışa neden olmuştur. Dolayısılyla $\mathrm{E} \approx 5-10 \mathrm{GPa}$ olan bir kaya için $\mathrm{Y} \approx 10 \mathrm{GPa}$ ' dan başlatılarak simülasyonlar çalıştırılabilir.

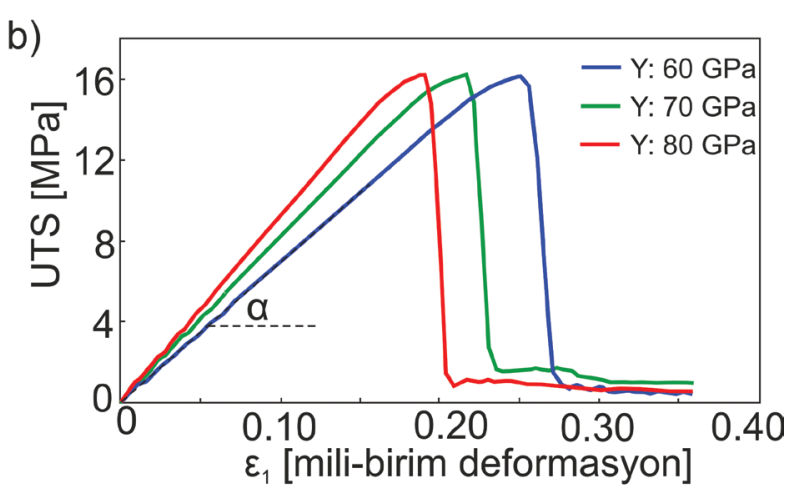

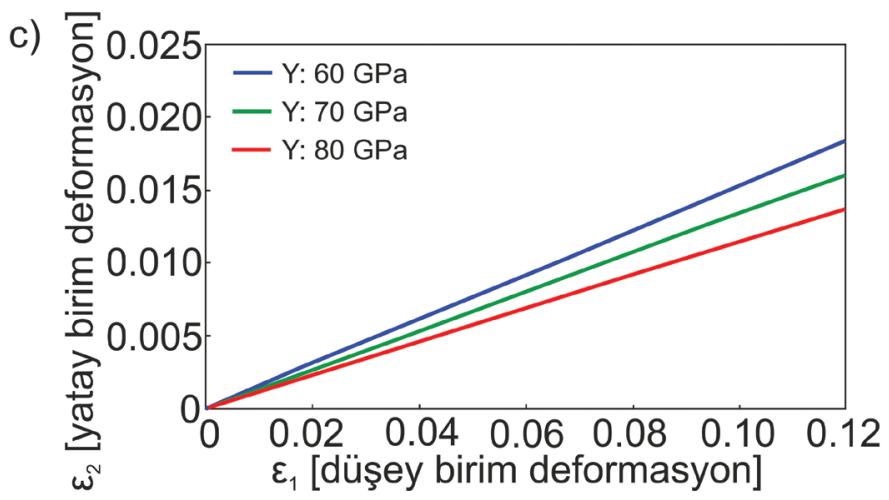

Şekil 6. Elastisite modülünün (Y) dayanım ve deformasyon özellikleri üzerindeki etkileri a) $Y^{\prime}$ nin UCS ve E üzerindeki etkisi $(\tan \alpha=E)$ b) Y' nin UTS ve $\mathrm{E}_{\text {cekme }}$ üzerindeki etkisi $\left(\tan \alpha=\mathrm{E}_{\text {cekme }}\right)$ c) Y' nin $v$ üzerindeki etkisi.

Figure 6. The effects of elastic modulus (Y) on rock strength and deformation properties a) effect of $Y$ on UCS and $E$ $(\tan \alpha=E)$ b) effect of $Y$ on UTS and $E_{\text {tensile }}\left(\tan \alpha=E_{\text {tensile }}\right)$ c) effect of $Y$ on $v$. 
Dinç Göğüş

\section{Koordinasyon Sayısı (N)}

Sayısal modeli oluşturan ayrık elemanlar/ partiküller birbirleriyle etkileşim halindedir ve etkileşim bir orana $\left(\gamma_{\text {int }}\right)$ tabidir. Her bir partikül başına düşen bağ sayısı $(\mathrm{N})$ bu orana göre belirlenmekte ve bu özellik sayesinde tanelerin birbirleriyle olan kenetlenme derecesi simülasyonlar henüz başlamadan kontrol edilebilmektedir. Söz konusu parametre, klasik bağlı partikül modellerinde (BPM) (Potyondy ve Cundall, 2004) karşılaş1lan ve doğru bir şekilde ayarlanamayan (UCS/UTS) oranı için oldukça kolay ve pratik bir yöntem olmuştur. Scholtès ve Donzé (2013) tarafından önerilen bu yöntem, Potyondy (2012) veya Ding ve Zhang (2014) tarafindan geliştirilen modifiye edilmiş BPM eşitliklerine bir alternatif olarak kullanılabilir. Aslında kenetlenme derecesi $\gamma_{\text {int }}$, in doğrudan bir fonksiyonu olduğundan $\mathrm{N}$ veya $\gamma_{\text {int }}$ kayanın mekanik davranışı üzerinde de doğrudan etkilidir. Örneğin $\gamma_{\text {int }} 1$ ' e yaklaştığında, simüle edilen malzeme zayıf bir kayayı temsile ederken, $\gamma_{\text {int }}$ ' in daha yüksek değerleri için daha sağlam ve rijit bir kaya davranışı sergilenmektedir. $\mathrm{Bu}$ nedenle $\mathrm{N}$ parametresi malzemenin dayanım karakteristiklerine göre kalibre edilmelidir. $\mathrm{Bu}$ çalışmada Forsmark granitlerinin (UCS/UTS) oranı yaklaşık olarak $12.5^{\prime}$ dir. Dolayısıyla etkileşim oranı $\gamma_{\text {int }}=1.46(\mathrm{~N}=13)$ olarak alınmıştır. Eğer (UCS/UTS) oranı daha düşük olsayd1, $\gamma_{\text {int }}($ veya $\mathrm{N})$ değerinin de azaltılması gerekecekti.

Bir dizi tek eksenli sıkışma ve çekme dayanımı deney simülasyonunda $\mathrm{N}$ parametresinin $\left(\right.$ veya $\left.\gamma_{\text {int }}\right)$ farklı değerleri için elde edilen UCS ve UTS sonuçları değerlendirilmiştir (Şekil 7). N değerindeki azalışa göre dayanım oranları dramatik bir şekilde azalmakta $(\mathrm{N}: 13$ için UCS/UTS: 12.4 ; N: 10 için UCS/UTS: 8.6 ve N: 8 için UCS/UTS: 6.8) ve bu durum giderek daha yumuşak bir kaya türüne geçildiğini göstermektedir. $\mathrm{Bu}$ nedenle yumuşak bir kaya için N değeri öncelikle 8' den, sert ve dayanıklı bir kaya için 11-12' den başlatılabilir.

Aşağıda bahsedilen her bir mikro parametrenin (c, t, $\phi, \mathrm{P}, \mathrm{Y}, \mathrm{N})$ kayanın makro mekanik özellikleri (UCS, UTS, E, $\mathrm{E}_{\text {çekme }}, \mathrm{v}$ ) üzerindeki etkisi ve simülasyon sonuçlarından elde edilen sayısal veriler Çizelge 3' de verilmiştir.

b)

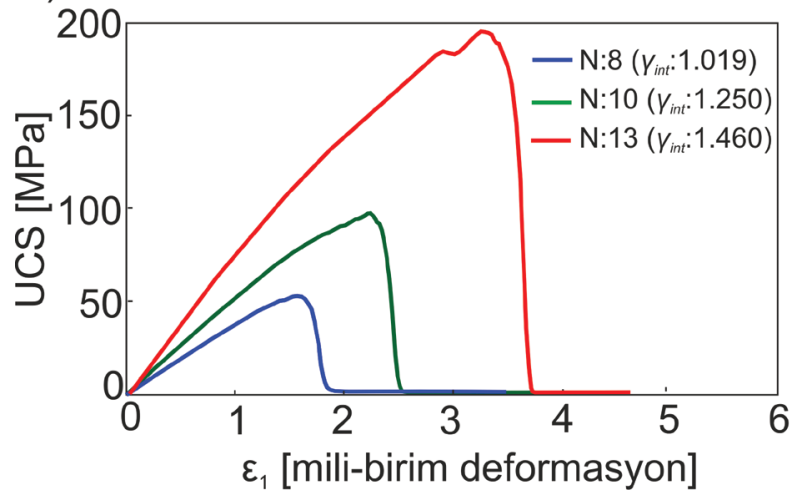

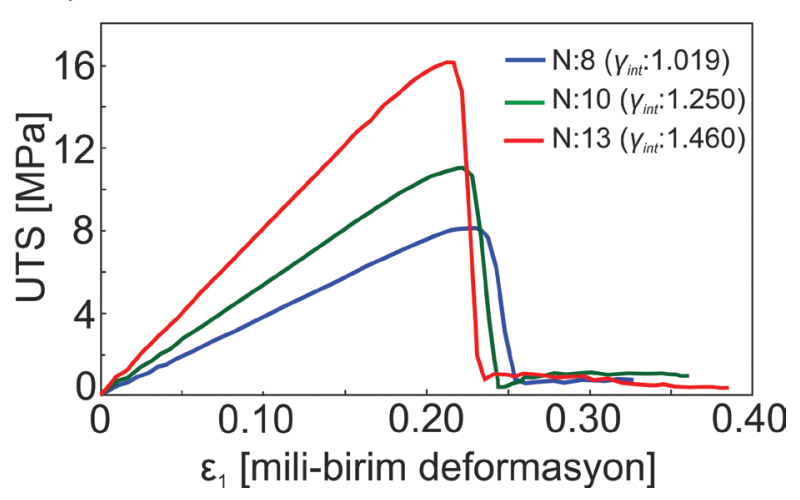

Şekil 7. Koordinasyon sayısının (N) dayanım üzerindeki etkisi a) N'nin UCS üzerindeki etkisi b) N' nin UTS üzerindeki etkisi.

Figure 7. The effect of coordination number (N) on rock strength a) effect of $N$ on UCS b) effect of $N$ on UTS. 
Çizelge 3. Mikro parametrelerdeki değişimin makro kaya özellikleri (UCS, UTS, E, $\mathrm{E}_{\text {cekme }}$, v) üzerindeki etkisi. Table 3. The effect of variations in micro parameters on macro properties of rock (UCS, UTS, E, $E_{\text {tensile }^{2}} v$ ).

\begin{tabular}{|c|c|c|c|c|c|}
\hline Mikro-parametreler & UCS (MPa) & UTS (MPa) & $\mathrm{E}(\mathrm{GPa})$ & $\mathrm{E}_{\text {cekme }}(\mathrm{GPa})$ & $v(-)$ \\
\hline \multicolumn{6}{|l|}{$\mathrm{c}(\mathrm{MPa})$} \\
\hline 13 & 65 & 16 & 75 & 80 & 0.13 \\
\hline 65 & 150 & 16 & 75 & 80 & 0.13 \\
\hline 130 & 199 & 16 & 75 & 80 & 0.13 \\
\hline 195 & 199 & 16 & 75 & 80 & 0.13 \\
\hline 260 & 199 & 16 & 75 & 80 & 0.13 \\
\hline 1300 & 200 & 16 & 75 & 80 & 0.13 \\
\hline \multicolumn{6}{|l|}{$\mathrm{t}(\mathrm{MPa})$} \\
\hline 10 & 145 & 12.5 & 75 & 80 & 0.13 \\
\hline 13 & 199 & 16 & 75 & 80 & 0.13 \\
\hline 15 & 220 & 18.5 & 75 & 80 & 0.13 \\
\hline \multicolumn{6}{|l|}{$* \phi\left({ }^{\circ}\right)$} \\
\hline 5 & 199 & 16 & 75 & 80 & 0.13 \\
\hline 10 & 199 & 16 & 75 & 80 & 0.13 \\
\hline 20 & 199 & 16 & 75 & 80 & 0.13 \\
\hline 40 & 210 & 16 & 75 & 80 & 0.13 \\
\hline \multicolumn{6}{|l|}{$\mathrm{P}(-)$} \\
\hline 0.2 & 95 & 14 & 67 & 66 & 0.17 \\
\hline 0.4 & 199 & 16 & 75 & 80 & 0.13 \\
\hline 0.6 & 275 & 18.5 & 90 & 100 & 0.09 \\
\hline \multicolumn{6}{|l|}{$\mathrm{Y}(\mathrm{GPa})$} \\
\hline 60 & 175 & 16 & 64.5 & 71 & 0.15 \\
\hline 70 & 199 & 16 & 75 & 75 & 0.13 \\
\hline 80 & 200 & 16 & 87 & 90 & 0.11 \\
\hline \multicolumn{6}{|l|}{$* * \mathrm{~N}(-)$} \\
\hline 8 & 55 & 8 & - & - & - \\
\hline 10 & 95 & 11 & - & - & - \\
\hline 13 & 199 & 16 & - & - & - \\
\hline
\end{tabular}

* $\phi$ değerindeki artış üç eksenli gerilim koşullarında doruk dayanım üzerinde etkilidir.

**N parametresinin her farklı değeri için sayısal model farklı etkileşim oranına sahip partikül topluluklarından oluştuğundan $\mathrm{E}_{\text {, }} \mathrm{E}_{\text {çekme }}$ ve $v$ birbiriyle karşılaştırılamaz. 
Dinç Göğüş

\section{TARTIŞMA VE SONUÇLAR}

Sayısal modelleme yöntemleri mühendislik projelerinin hızlandırılması ve pratik sonuçlar üretmesi bakımından son yıllarda sıklıkla başvurulan bir yöntem olmuştur. Ancak bu yöntemlerin ürettiği verilerin güvenilirliği tartışmaya açık olmamalı ve kurulan modeller gerçek malzemenin mekanik davranışını tam olarak yansıtmalıdır. Özellikle klasik ağ tabanlı sürekli yöntemlerde, sonuçların sınır koşullarından etkilendiği bilinmektedir. Buna karşın bir modelin mekanik özelliklerinin ölçek etkisi, model boyutu/çözünürlüğü gibi fiziksel faktörlerden bağımsız olması gerekmektedir. Söz konusu yaklaşımdan yola çıkarak bu çalışmada ayrık elemanlar yöntemine dayanan sayısal bir modelin kalibrasyonu sirasında dikkat edilmesi gereken noktalar analizlerle açıklanmıştır. Çok sayıda tek ve üç eksenli sıkışma, tek eksenli çekme testi simülasyonunun gerçekleştirildiği çalışmada modelin temsil ettiği kaya türü Forsmark granitleridir. Sayısal analizlerden elde edilen tüm sonuçlar aşağıda özetlenmiştir:

- Ayrık elemanlar yöntemiyle (DEM) oluşturulan bir kaya modelinin bağl1 partikül model (BPM) formülasyonuna göre 6 adet mikro parametresi [(kohezyon (c), çekme dayanımı (t), içsel sürtünme açısı $(\phi)$, rijitlik oranı $(\mathrm{P})$, elastisite modülü $(\mathrm{Y})$ ve partiküller aras1 bağ sayısı (N)] bulunmaktadır ve mikro parametreler kayanın makro mekanik özelliklerini [(tek eksenli sıkışma dayanımı (UCS), tek eksenli çekme dayanımı (UTS), Young modülleri ( $\mathrm{E}_{\mathrm{ve}} \mathrm{E}_{\text {çekme }}$ ), Poisson oran1 (v)] doğrudan etkilemektedir.

- c değerinin artması UCS' yi artırırken, UTS ise değişmemektedir.

- $\quad t$ değerinin artması hem UCS hem de UTS' yi arttırmaktadır.
- $\quad \phi$ değerinin tek eksenli gerilme koşullarında kayanın dayanım özellikleri üzerinde belirgin bir etkisi bulunmamıştır. Diğer taraftan üç eksenli sıkışma rejimi altında yanal basıncin artmasıyla doruk dayanım değeri artmış ve böylece kayaya ait HoekBrown yenilme zarfının eğimi de artmıştır.

- P değerindeki değişim, kayanın tüm mekanik özellikleri üzerinde etkili olmuştur. P değeri artarken UCS, UTS, E, $\mathrm{E}_{\text {çekme }}$ değerleri de artmaktadır. Buna karşılık $v$ değeri azalmaktadır.

- $\quad \mathrm{Y}$, kayanın deformasyon özellikleri üzerinde etkilidir. $\mathrm{Y}$ artarken, $\mathrm{E}$ ve $\mathrm{E}_{\text {çekme }}$ de artmış ancak $v$ değeri azalışa geçmiştir. Kayanın gerilim-deformasyon eğrisinin lineer elastik kısmında belirgin bir eğim artış1 gözlemlenmiştir.

- $\quad \mathrm{N}$ değeri kayanın dayanım özelliklerine göre simülasyon öncesinde kalibre edilmektedir. Bu çalışmada sayısal modelin temsil ettiği kaya türü sert ve dayanıklı bir kaya olduğundan, $\mathrm{N}$ değerinin nispeten büyük tutulması gerekmiştir. Çünkü $\mathrm{N}$ değeri doğrudan (UCS/UTS) oranına göre atanmaktadır. Farklı N değerleri için yapılan deney simülasyonlarında, $\mathrm{N}$ değerindeki azalmayla birlikte dayanım oranı da azalmaktadır.

Model sonuçlarından bir parametrenin, bir kayaya ait birden fazla özellik üzerinde etkisi olabildiği anlaşılmaktadır. Bu durumu gözönünde bulundurarak, kalibrasyon sırasında düzenli bir şekilde diğer parametrelerin atanan değerden nasıl etkilendiği kontrol altında tutulmalıdır. Sayısal modeller doğru bir şekilde kurulduğunda, laboratuvarda veya arazide yapılan deneylerde karşılaşılan ve gözardı edilen ölçek etkisi gibi bir faktörün tamamen dikkate alınabileceği bir analiz platformu sağlayabilir. Bu tür yöntemler temsil 
edici şekilde geliştirildiğinde, yalnızca karot ölçeğinde değil, örneğin bir yeraltı operasyonu gibi bölgesel-yapısal ölçekteki kayalarda oluşabilecek deformasyonların kestirilebilmesi açısından oldukça yararlı veriler sunabilmektedir.

\section{KATKI BELÍRTME}

$\mathrm{Bu}$ çalışma İstanbul Teknik Üniversitesi - Bilimsel Araştırma Projeleri Koordinasyon Biriminin MUA-2019-42012 nolu projesi tarafından desteklenmiştir.

\section{KAYNAKLAR}

Al-Busaidi, A., Hazzard, J.F., Young, R.P., 2005. Distinct element modeling of hydraulically fractured Lac du Bonnet granite. Journal of Geophysical Research Atmospheres, 110 (6), doi: 10.1029/2004JB003297.

Beniawski, Z.T., 1968. The effect of specimen size on compressive strength of coal. International Journal of Rock Mechanics and Mining Sciences, $5,325-335$.

Cho, N., Martin, C.D., Sego, D.C., 2007. A clumped particle model for rock. International Journal of Rock Mechanics and Mining Sciences, 44, 997-1010.

Cundall, P.A., 1971. A computer model for simulating progressive, large scale movements in blocky rock systems. Proceedings of the International Symposium on Rock Mechanics, Nancy, France, 129-136.

De Borst, R., Sluys, L.J., Mulhaus, H.B., Pamin, J., 1993. Fundamental issues in finite element analyses of localization of deformation, Engineering Computations, 10(2), 99-121.

Deisman, N., Mas Ivars, D., Darcel, C., Chalaturnyk, R.J., 2009. Empirical and numerical approaches for geomechanical characterization of coal seam reservoirs. International Journal of Coal Geology, doi:10.1016/j.coal.2009.11.003.
Dinç, Ö., Scholtès, L., 2018. Discrete analysis of damage and shear banding in argillaceous rocks. Rock Mechanics Rock Engineering, 51(5), 1521-1538.

Dinç Göğüş, Ö., 2020. 3D discrete analysis of damage evolution of hard rock under tension, Arabian Journal of Geosciences, https://doi.org/10.1007/ s12517-020-05684-1,13, 661.

Ding., X., Zhang, L., 2014. A new contact model to improve the simulated ratio of unconfined compressive strength to tensile strength in bonded particle models. International Journal Rock Mechanics Mining Science, 69, 111-119.

Duan, K., Kwok, C., 2016. Evolution of stress-induced borehole breakout in inherently anisotropic rock: insights from discrete element modeling. J Geophys Res Solid Earth, 121, 2361-2381.

Duan, K., Kwok, C., Pierce, M., 2015. Discrete element method modeling of inherently anisotropic rocks under uniaxial compression loading. International Journal for Numerical and Analytical Methods in Geomechanics, http s:// doi.org/10.1002 /nag.2476.

Glamheden, R., Lanaro, F., Karlsson, J., Wrafter, J., Hakami, H., Johansson, M., 2008. Rock mechanics Forsmark Modelling stage 2.3 Complementary analysis and verification of the rock mechanics model. https://www.skb. se/publikation/1924849/R-08-66.pdf, Swedish Nuclear Fuel and Waste Management Co, SKB Rapport R-08-66.

Goodman, R.E., 1989. Introduction to Rock Mechanics. John Wiley \& Sons, University of California at Berkeley, $562 \mathrm{p}$.

Hamdi, J., Souley, M., Scholtès, L., Al Heib, M., Gunzburger, Y., 2017. Assessment of the energy balance of rock masses through discrete element modelling. Procedia Engineering, 191, 442 450 .

Hazzard, J.F., Young, R.P., Maxwell, S.C., 2000. Micromechanical modeling of cracking and failure in brittle rocks. Journal of Geophysical Research, 105(7), 16683-16697. 
Dinç Göğüş

Heuze, F., 1980. Scale effects in the determination of rock mass strength and deformability. Rock Mechanics, 12, 167-192.

Jacobsson. L., 2007. Forsmark site investigation Boreholes KFM01A and KFM02B - Micro crack volume measurements and triaxial compression tests on the intact rock. https://www.skb.se/ publikation/1606317/P-07-93.pdf, Swedish Nuclear Fuel and Waste Management Co, SKB P-07-93.

Lanaro. F, Fredriksson, A., 2005. Rock Mechanics Model - Summary of the primary data - Preliminary site description Forsmark area - version 1.2. https://www.skb.se/ publikation/1107184/R-05-83.pdf, Swedish Nuclear Fuel and Waste Management Co, SKB Rapport R-05-83.

Lisjak, A., Tatone, B., Mahabadi, O.K., Grasselli, G., Marschall, P., Lanyon, G.W., de la Vaissie`re, R., Shao, H., Leung, H., Nussbaum, C., 2016. Hybrid Finite-Discrete Element Simulation of the EDZ formationand mechanical sealing process around a microtunnel in opalinus clay. Rock Mechanics Rock Engineering, 49, 1849-1873.

Medhurst, T.P., Brown, E.T., 1998. A study of the mechanical behaviour of coal for pillar design. International Journal of Rock Mechanics and Mining Sciences and Geomechanics Abstracts 35(8), 1087-1105.

Moosavi, S., Scholtès, L., Giot, R., 2018. Influence of stress induced microcracks on the tensile fracture behavior of rocks. Computers and Geotechnics, 104, 81-95.

Pardoen, B., Seyedi, D.M., Collin, F., 2015. Shear banding modelling in cross-anisotropic rocks. International Journal of Solids and Structures, 72, 63-87.

Plassiard, J.P., Belheine, N., Donzé, F.V., 2009. A spherical discrete element model: calibration procedure and incremental response. Granular Matter, doi: 10.1007/s10035-009-0130-x.
Potyondy, D.O, Cundall, P.A., Lee, C.A., 1996. Modelling rock using bonded assemblies of circular particles. 2nd North American Rock Mechanics Symposium; 1996 Montreal Canada, 1937-1944.

Potyondy, D.O., Cundall, P.A., 2004. A bondedparticle model for rock. International Journal of Rock Mechanics and Mining Science, 41(8), 1329-1364.

Potyondy, D.O., 2012. A flat-jointed bonded-particle material for hard rock. In: Proceedings of the 46th US rock mechanics/geomechanics symposium, American Rock Mechanics Association, Chicago, USA.

Scholtés, L., Donzé, F.V., 2012. Modelling progressive failure in fractured rock masses using a 3D discrete element method, International Journal of Rock Mechanics and Mining Sciences, 52, $18-30$.

Scholtés, L., Donzé, F.V., 2013. A DEM model for soft and hard rocks: role of grain interlocking on strength. Journal of the Mechanics and Physics of Solids, 61, 352-369.

Scholtés, L., Donzé, F.V., 2015. A DEM analysis of step-path failure in jointed rock slopes, Mechanics of granular and polycrystalline solids, Comptes Rendus Mécanique, 343(2), 155-165.

Šmilauer, V. et al., 2015. Yade documentation, 2nd edn. The Yade Project. http ://yade -dem.org/ doc/. http s://doi.org/10.5281/zeno do.34073.

Wang, Y., Tonon, F., 2009. Modeling Lac du Bonnet granite using a discrete element model. International Journal of Rock Mechanics and Mining Sciences, 46, 1124-1135. 